\title{
ANÁLISE DA IMPRENSA COMO FONTE DE PESQUISA PARA A HISTÓRIA DA EDUCAÇÃO
}

\author{
ANÁLISIS DE LA PRENSA COMO FLUENTE DE INVESTIGACIÓN PARA LA \\ HISTÓRIA DE LA EDUCACIÓN
}

\author{
ANALYSIS OF THE PRESS AS A RESEARCH SOURCE FOR THE HISTORY \\ OF EDUCATION
}

\author{
Claudia Maria Petchak ZANLORENZI ${ }^{1}$ \\ Maria Isabel Moura NASCIMENTO
}

RESUMO: Os estudos em história da educação que utilizam a imprensa como fonte primária ou secundária vêm aumentando significativamente e contribuído sobremaneira para a compreensão de que os processos históricos são mediados e fazem parte de uma totalidade. Utilizar- se de outras fontes que não especificamente as do contexto escolar auxilia na apreensão das permanências e rupturas dos processos educacionais atuais, pois apontam os debates e a ressonância dos mesmos do contexto social, dando subsídios para o entendimento das relações sociais, políticas, econômicas e culturais. Tendo como pressuposto teórico o materialismo histórico, o presente artigo tem por objetivo apresentar uma proposta de análise da imprensa como fonte de pesquisa para a história da educação. Para tanto, primeiramente serão feitos apontamentos sobre a imprensa como fonte de pesquisa e na sequência uma proposição para a análise da imprensa. É importante salientar que não se tem nenhuma receita pronta, cada pesquisador faz o seu caminho e suas escolhas, não existe certo ou errado, apenas escolhas, para não cairmos em um determinismo reducionista ou engessarmos nas práticas ou representações em si mesmo ou para si.

PALAVRAS-CHAVE: História da educação. Fonte. Imprensa.

RESUMEN: Los estudios en historia de la educación que utilizan la prensa como fuente primaria o secundaria vienen aumentando significativamente y contribuido sobremanera para la comprensión que los procesos históricos son mediados y forman parte de una totalidad. El uso de otras fuentes que no específicamente las del contexto escolar, auxilian en la aprehensión de las permanencias y rupturas de los procesos educativos actuales, pues apuntan los debates y la resonancia de los mismos del contexto social, dando subsidios para el entendimiento de las relaciones sociales, políticas, económicas y culturales. Con el supuesto teórico del materialismo histórico, el presente artículo tiene por objetivo presentar una propuesta de análisis de la prensa como fuente de investigación para la historia de la

${ }^{1}$ Universidade Estadual do Paraná (UNESPAR), União da Vitória - PR - Brasil. Professora Adjunta. Integrante do Grupo de Pesquisa HISTEDBR e do Grupo de Estudo e Pesquisa em Educação: teoria e prática /Núcleo de Estudos de Fundamentos da Educação e Métodos (NEFEM - UNESPAR/UV). Doutora em História e Políticas Educacionais (UNESPAR). ORCID: http://orcid.org/0000-0002-8937-6308. E-mail: aecmari@gmail.com ${ }^{2}$ Universidade Estadual de Ponta Grossa (UEPG), Ponta Grossa - PR - Brasil. Professora Associada e Professora no curso de graduação em Educação e no Programa de Pós-Graduação em Educação. Membro do Comitê Científico de Ciências Humanas do PIBIC/CNPq -UEPG. Pós-Doutorado em História e Filosofia da Educação (UNICAMP). ORCID: http://orcid.org/0000-0001-6243-9973. E-mail: misabelnasc@ gmail.com 
educación. Para ello, primero se harán apuntes sobre la prensa como fuentes de investigación y en la secuencia una propuesta para el análisis de la prensa. Es importante resaltar que no se tiene ninguna receta lista, cada investigador hace su camino y sus elecciones, no hay el cierto o equivocado, sólo elecciones, para no caer en un determinismo reduccionista o enyesarnos en las prácticas o representaciones en sí mismo o para sí.

PALABRAS CLAVE: Historia de la educación. Fuente. Prensa.

ABSTRACT: Studies on history of education that uses the press as a primary or secondary source is increasing significantly and contributed greatly to an understanding that the historical processes are mediated and are part of a totality. Using other sources other than specifically of those of the school context assists to the comprehension of the permanency and ruptures of current educational processes, because it points out to debates and the resonance of the same social context, giving subsidies to the understanding of social, political, economic and cultural relations. Having as theoretical presupposition the historical materialism, this article aims to present a proposal for the analysis of the press as a source for the history of education. For this purpose, firstly notes will be taken about the press as a research source and then a proposition for the analysis of the press. It is important to emphasize that there's no ready recipe, each researcher makes his own way and choices, there is no right or wrong, only choices, so we don't fall in a reductive determinism or don't be strict in the practices or representations in itself or for itself.

KEYWORDS: History of education. Source. Press.

\section{Introdução}

Os estudos em história da educação que utilizam a imprensa como fonte primária ou secundária vêm aumentando significativamente e contribuído sobremaneira para a compreensão que os processos históricos são mediados e fazem parte de uma totalidade.

Utilizar-se de outras fontes que não especificamente as do contexto escolar auxilia na apreensão das permanências e rupturas dos processos educacionais atuais, pois apontam os debates e a ressonância dos mesmos do contexto social, dando subsídios para o entendimento das relações sociais, políticas, econômicas e culturais.

Neste sentido, o presente artigo tem por objetivo apresentar uma proposta de análise da imprensa como fonte de pesquisa para a história da educação. Para tanto primeiramente serão feitos apontamentos sobre a imprensa como fonte de pesquisa e na sequência uma proposição para a sua análise. É importante salientar que esta proposta não é engessada e linear, mas um caminho para auxiliar na pesquisa tendo como fonte de pesquisa a imprensa. 


\section{Fontes para os estudos sobre a História da Educação}

Compreender os processos históricos que permeiam a educação e as contradições que constituem estes processos não se resume às explicações positivistas de causas e efeitos, mas sim à possiblidade de verificar as mediações presentes na totalidade. Neste sentido sim, é possível analisar a forma como são estabelecidas as relações entre os sujeitos, permeadas pelas relações de produção, sendo que a educação é reflexo destas relações.

Assim, para o estudo da história da educação é primordial verificar as questões econômicas, sociais, culturais e políticas do contexto, que se influenciam mutuamente, e principalmente a ideologia que as mantém, direcionando as instituições que fazem parte da sociedade, como por exemplo, a escola.

Local onde se materializa o processo de ensino, ou melhor, o trabalho não material (SAVIANI, 2012, p. 12) e seu produto, a escola é o campo em excelência para as pesquisas históricas. $\mathrm{O}$ estudo das instituições escolares tem se caracterizado como promissor, uma vez que conta com inúmeras fontes que possibilitam pesquisas empíricas: desde os materiais pedagógicos até a arquitetura, além das narrativas utilizadas principalmente pela perspectiva da História Cultural.

Neste processo empírico de produção de conhecimento, é primordial o posicionamento teórico e metodológico do pesquisador, ou seja, “[...] do mirante de onde olha e este lhe dá o seu alcance e o seu limite. Mirantes teóricos mais elevados viabilizam um olhar sobre horizontes mais distantes" (SANFELICE, 2005, p. 85). Independente do aporte teórico, é primordial o fortalecimento das pesquisas em história da educação, a fim de demonstrar que estudos que tratam dos sujeitos, seja qual for a área, são estudos históricos, pois a práxis é uma produção histórica.

Atualmente, além da análise da cultura escolar com suas fontes específicas ambientes e práticas, instrução formalizada -, verificam-se proeminências nas pesquisas em utilizar outras fontes que não relacionadas diretamente com o processo educativo, a depender do objeto de estudo, mas que se tangenciam, ampliando o campo de pesquisa, superando os enfoques cartesianos e a lógica formal, impulsionando para novos procedimentos metodológicos.

Campo de discussões teóricas e metodológicas, estas pesquisas têm se constituído em ambientes que ultrapassam os muros dos espaços institucionalizados, ou seja, utilizando outras formas de fontes, bem como novas formas de inquiri-los, ocasionando a ressignificação do conceito de documento. 
A riqueza do diálogo das fontes com as teorias é, portanto, a possibilidade de além de problematizar a ambas, alterar as representações que temos não só delas, mas também da própria pesquisa histórica. É evidente que tais representações não são apenas criações do espírito, mas produtos da mentalidade de uma certa época, de certas categorias sociais e determinados grupos. (NUNES; CARVALHO, 1993, p. 32).

Tratar sobre fonte é considerar que não há uma hierarquização entre o material que irá compor a pesquisa, ou melhor, que há fontes que supõem maior credibilidade, ou ainda, que para pesquisa em educação, as fontes devem ser necessariamente do contexto escolar. Diante do exposto, faz-se necessário refletir sobre o termo fonte, que pressupõe várias acepções. Primeiramente, fonte vem do latim fontis, que significa nascente de água, chafariz (CUNHA, 1986, p. 364). Discutindo os termos que compõe o seu significado, fonte como nascente, reporta-se como origem, causa e fundamento. Como fundamento, é característica daquilo que fundamenta a informação, opinião, estudo, “[...] o ponto de partida da construção historiográfica que é a reconstrução, no plano do conhecimento, do objeto histórico estudado.” (SAVIANI, 2004, p. 05).

Caso seja considerado o termo fonte como origem, as pesquisas em história da educação que se utilizam das fontes específicas do contexto escolar seriam mais adequadas às reflexões das considerações assertivas e conclusivas. Sendo assim, o universo escolar por si só daria conta das problemáticas que a educação carrega até os dias atuais. Porém, caso se considere a educação como parte de uma totalidade, sendo ela também uma própria totalidade e reflexo do modo de produção, ultrapassar os muros escolares possibilita verificar as contradições que envolvem a sociedade e assim um alargamento do que é fonte para a história da educação, bem como "[...] preparar o terreno para uma crítica empírica vigorosa que constitui novos problemas, novos objetos, novas abordagens." (NUNES; CARVALHO, 1993, p. 30).

Neste sentido, destaca-se a utilização da grande imprensa, como revistas e jornais, tanto os diários como os de cunho pedagógico, campo em que pode ser analisada a complexidade dos conflitos, dos projetos políticos, das visões de mundo:

[...] a imprensa, ligada à educação, constitui-se em um "corpus documental" de inúmeras dimensões, pois se consolida como testemunho de métodos e concepções pedagógicas de um determinado período. Como também da própria ideologia moral, política e social, possibilitando aos historiadores da educação análises mais ricas a respeito dos discursos educacionais. (CARVALHO; ARAÚJO; GONÇALVES NETO, 2002, p. 72). 
Campo para novas perspectivas de análise dos processos históricos, ao mesmo tempo campo tênue de um paradoxo - defensora da opinião pública e dos fatos reais e expressão tendenciosa de uma ideologia - sobre a égide da imparcialidade, a imprensa se constitui a possibilidade de "[...] visualizar horizontes mais diversificados, como também múltiplas aproximações em relação a estas questões ligadas ao campo educacional.” (CARVALHO; ARAÚJO; NETO, 2002, p. 74). O estudo desta fonte requer a efetiva reflexão de que o material expresso na imprensa é multideterminado, o que requer o cuidado em não somente considerá-lo como veículo das ideias, reflexo da infraestrutura econômica, mas também como possibilidade de um espaço de denúncia e campo de conflito.

\section{Imprensa como fonte de pesquisa}

Imaginando uma certa realidade para pesquisa, um geógrafo poderia estar interessado com a energia dos alimentos que se movem entre os diferentes componentes da biosfera, um matemático, nas dinâmicas das equações, um economista, talvez, na área de avaliação de políticas públicas, e assim por diante. O que se está querendo marcar é que a realidade, não é só a que é conhecida, pois a realidade é dinâmica, perversa, injusta e desigual. E na investigação científica com a imprensa, precisamos pensar que tudo está além dos nossos olhos, na unidade da diversidade (MARX, 2003), por isso um trabalho científico é contínuo, cujo movimento necessita ser reconstruído pelo historiador.

Com o intuito de apontar uma proposição de pesquisa com a imprensa, é primordial que o pesquisador realize o Estado do Conhecimento, considerado aqui o estudo das teses e dissertações que utilizam a imprensa como fonte primária.

O Estado de Conhecimento (ou estado da arte) é um tipo de pesquisa que visa a um aprofundamento da produção acadêmica sobre uma temática em especial. Esta forma de investigação proporciona um parâmetro sobre a quantidade das pesquisas efetivadas e, mediante esta análise, há a aceitação do objeto, as convergências e divergências, os pressupostos teóricos e as lacunas, bem como as inovações na área $\mathrm{e}$ as permanências. (NASCIMENTO; ZANLORENZI, 2017, p. 18)

Como possibilidade, o pesquisador pode realizar um levantamento na Biblioteca Digital de Teses e Dissertações (BDTD) e analisar as pesquisas em relação a sua proposta, bem como observar as potencialidade e fragilidades, o que poderá indicar um caminho para seu próprio trabalho. Por exemplo, a partir dos indexadores: revista, história da educação, no recorte teórico de 2007 a 2017, verificou-se que neste período há quarenta e sete (47) 
pesquisas entre teses e dissertações, de diversos programas de pós-graduação em educação, que tratam da história da educação a partir das revistas educacionais como fontes. Com este esboço, observa-se que a utilização da imprensa cresceu de forma significativa, porém os trabalhos em história da educação que se dedicam a estudar as revistas de cunho educacional ainda são em número restrito.

Analisando o método de investigação das pesquisas acima apresentadas, observou-se que grande parte tem a História Cultural como embasamento teórico, conforme apresentado na figura 1 abaixo:

Figura 1 - Gráfico com métodos de pesquisa

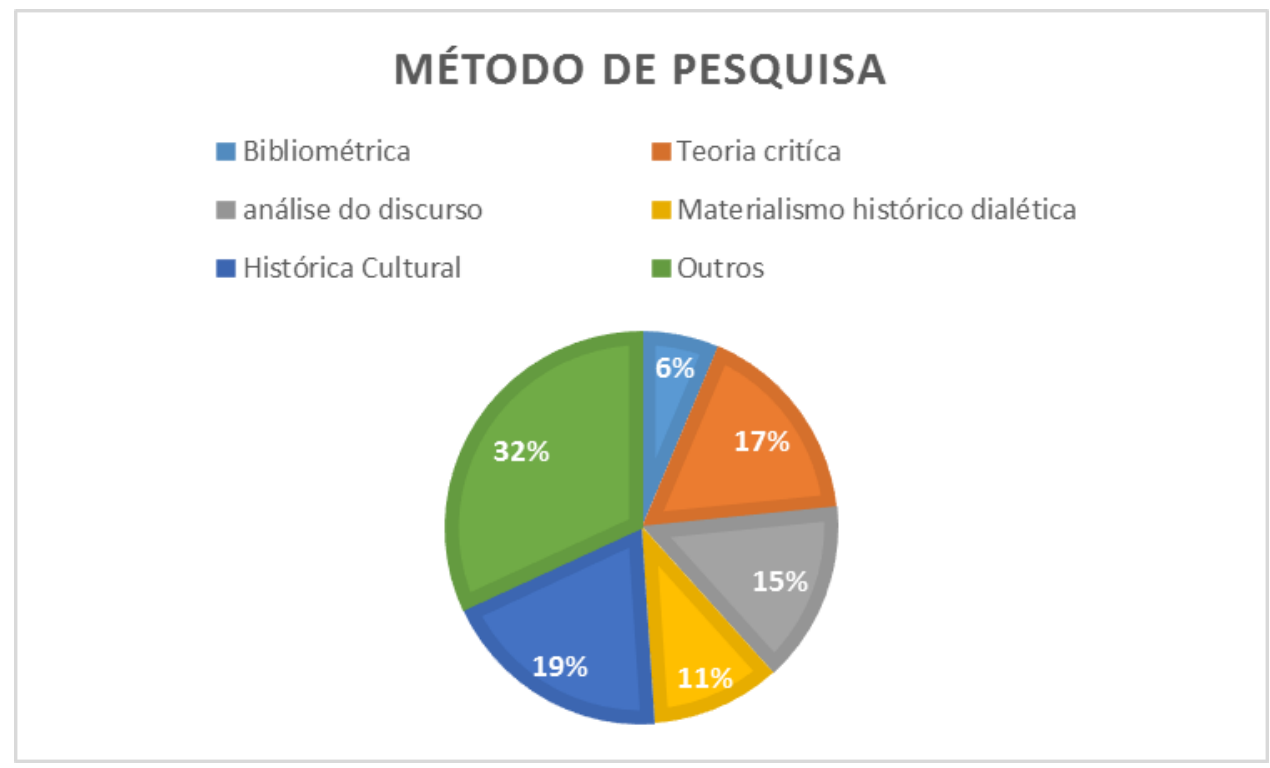

Fonte: Elaborado pelas autoras.

Além do número de pesquisas que utilizam as revistas como fonte, o aporte metodológico também é uma a qual informação deve ser dada a devida atenção. Uma fragilidade que suscitou desta verificação é que uma porcentagem de pesquisas que não se posicionam em relação ao método, e somente apresentam o procedimento metodológico em relação ao tratamento da fonte. Todo trabalho de pesquisa deve contribuir para a problematização da sociedade nos seus diversos campos, porém descrever o fato sem uma devida atenção para as multideterminações do objeto pesquisado caracteriza-se tão somente como ilustração, contribuindo assim para manutenção do status quo, uma vez que não há questionamentos sobre a realidade.

Tendo como parâmetro as pesquisas que utilizam a imprensa, o pesquisador, na sequência, realiza o estudo da fonte que será utilizada. A importância de estudar o material de forma a não apenas conhecê-lo nos seus aspectos objetivos aponta para a compreensão que 
esta fonte está inserida numa sociedade, fruto de um modo como os homens produzem sua vida, haja vista que "O que eles são coincide, pois, com sua produção, tanto com o que produzem, como também com o modo como produzem. O que os indivíduos são, portanto, depende das condições materiais de sua produção.” (MARX; ENGELS, 2007, p. 87).

Outra questão que se faz importante é a periodização do estudo, e para isso o estado do conhecimento poderá colaborar para que se perceba qual o período histórico, se a pesquisa já foi trabalhada ou não e de que forma abordá-la. O pesquisador poderá estudar períodos mais recentes ou não, o importante é estar em consonância com o pressuposto adotado na pesquisa.

Neste sentido, o pesquisador deve compreender que o seu objeto está inserido num contexto histórico e que deve ser analisado, principalmente porque este se apresenta de forma caótica (síncrese), ou melhor, “[...] captado numa visão caótica, isto é, não se tem clareza do modo como ele é constituído. Aparece, pois, sob a forma de um todo confuso, portanto, como um problema que precisa ser resolvido.” (SAVIANI, 2007, p. 16).

Faz-se necessário contextualizar o periódico nos seus aspectos históricos com a análise do contexto em que o mesmo foi produzido, ou seja, as questões sociais, econômicas e políticas no período de sua publicação. Independente se o mesmo era um jornal local, de grande circulação, ou um periódico específico, como o educacional, é primordial compreender as relações que permeavam esta sociedade na totalidade de relações que a determina, sejam elas de nível econômico, social, cultural, e em suas contradições e mediações. O conhecimento do modo de produção vigente ou no período da pesquisa demonstra como se organizam as relações na sociedade. Todavia é primordial a apreensão de que a "[...] a realidade não se dá a conhecer imediatamente. Ela, por ser complexa, intrincada, apresenta múltiplas facetas [...]”. (IANNI, 2011, p. 397). Diante disso, a fonte deve ser considerada como histórica e não deve prender-se nos seus aspectos aparentes, na sua imediticidade, e sim, questionar e analisar de onde este objeto se compõe. Outrossim, é necessário historicizar o objeto pesquisado e articular as particularidades com a totalidade e o movimento apreendido desta relação dialética.

Destaca-se a necessidade da racionalidade na análise deste material. Por tanto, " [...] a observação empírica tem de provar, em cada caso particular, empiricamente e sem nenhum tipo de mistificação ou especulação, a conexão entre a estrutura social e política e a produção." (MARX; ENGELS, 2007, p. 93). Sendo assim, considerados os aspectos históricos, em seguida o pesquisador irá verificar os aspectos formais e materiais do periódico. Neste sentido, destacam-se os seguintes apontamentos: origem do jornal (local de publicação; data da fundação); proprietários e diretores do jornal (vínculos políticos- 
ideológicos); proposta do mesmo (a proposta de temática principal, a posicionamento do editorial, as temáticas proeminentes, principais campanhas encampadas pelo jornal); corpo de redação do jornal (editorialista e articulistas; vínculos com o objetivo do periódico). (ZICMAN, 1985).

Feito este estudo, na sequência, o pesquisador aponta os aspectos formais da fonte pesquisada, ou seja, nome (elemento de reconhecimento e de identificação do jornal), qualidade do jornal, formato, número de páginas, tipografia: tamanho, tipo de impressão, ilustrações (fotos, desenhos, caricaturas, gráficos, etc.), composição (organização e distribuição das colunas e secções: disposição dos textos, títulos e ilustrações no interior das páginas do jornal), sistema de títulos ( títulos, sub-títulos das matérias e artigos), os quais apontam o interesse do periódico, a sua finalidade e objetivos. Na sequência, realiza-se a averiguação dos aspectos financeiros: tiragem, que aponta a relevância do jornal; doações; assinaturas e vendas avulsas; anúncios publicitários; publicidade difusão: sistema de vendas e de distribuição, preço: estabelecer relações com custo-de-vida, salário-médio e número de páginas do jornal, destinatários, seção de "carta ao leitor". Estas indicações são sobremaneira identificadores do público leitor e da ressonância dos debates veiculados no material impresso. (ZICMAN, 1985).

Para esta verificação, há autores 3 que pesquisam a imprensa e propõem o ciclo de vida do periódico, entretanto, é necessário o extremo cuidado do pesquisador e que o mesmo ultrapasse esta análise, para que a mesma não se resuma apenas nas descrições exaustivas da fonte, que proporcionam somente uma análise da superfície do objeto. É primordial problematizá-la com reflexões articuladas, o que implica "[...] que o pesquisador se coloque diante do fato, sempre interrogando o fato sobre todos os aspectos, sobre todas as perspectivas." (IANNI, 2011, p. 397).

O estudo deve verificar a frequência da discussão sobre o tema na fonte; $n^{\circ}$ de vezes que aparece; localização do tema no interior das páginas do jornal; seção ou coluna do jornal em que aparece; destaque dado; tipo de matéria dedicada (editorial, reportagem, entrevista, crônica, etc.). É válido, neste momento da pesquisa, a utilização de tabelas e outros recursos para uma visão geral da temática, bem como auxiliar na análise, principalmente, na escrita do trabalho que se utilizará de excertos da fonte. A ausência da temática também é objeto de problematização, pois a mesma pode estar implícita de forma sutil e ideológica.

${ }^{3}$ Catani (2003), Leher (2002). 
Diante do exposto, a fase seguinte é o momento em que o pesquisador irá necessitar posicionar-se em se tratando do método de pesquisa, ou seja, o mirante em que irá analisar o seu objeto e a temática estudada nos artigos concernentes encontrados e selecionados entre os exemplares consultados. Vale salientar que é necessário que o pesquisador tenha a clareza do objeto de pesquisa, que não necessariamente pode ser o jornal, mas o tema que é o objetivo do estudo e que muitas vezes não está explícito, mas nas entrelinhas dos artigos. Por isso, a importância da contextualização histórica como aporte para compreender as relações de produção.

É necessário que o pesquisador tenha consciência que essa fonte expressa o ponto de vista daqueles que a produzem, o que significa que pode ser tendencioso e/ou estar compromissado. O pesquisador deve buscar então, a partir desse ponto, ampliar sua apreciação para além dos aspectos formais, pois não há uma disputa entre o certo e o errado, mas a busca do desvelamento das ideologias presentes e a forma de persuasão utilizada, para influir socialmente.

Em se tratando de pesquisas sobre a educação, os periódicos educacionais constituem “[...] um 'corpus documental' de inúmeras dimensões, pois consolida-se como testemunho de métodos e concepções pedagógicos de um determinado período" (CARVALHO; ARAÚJO; NETO, 2002, p. 72, grifos dos autores). As ideias educacionais veiculadas nesses impressos são a expressão do contexto histórico de forma imediata e dos interesses subjacentes, dado ser determinada pelo modo de produção. As reflexões pedagógicas que compõem este material estão muito próximas dos acontecimentos, como qualquer outra imprensa, verificados nos temas debatidos e na sua ressonância no contexto social, fato que possibilita vislumbrar, de maneira preponderante, os interesses e as influências registradas em suas folhas, direcionadas à educação, expressão de fatores políticos, sociais, culturais e econômicos. (ZANLORENZI; NASCIMENTO, 2013).

A pesquisa envolvendo a imprensa e os aspectos educacionais pressupõe entender que esta circula na sociedade vinculada a um movimento mais amplo da sociedade, podendo ser observado na veiculação de teorias e metodologias e na ressonância e aceitação do repertório expresso. "Conhecer a história através da imprensa pressupõe um trabalho com método rigoroso, tratamento adequado de fonte e reflexão teórica." (CAPELATO, 1988, p. 23).

A análise implica em recuperar a história, com a intenção não apenas de desvendar o passado, mas com o intuito de colaborar na compreensão dos processos educacionais atuais, pois 
O conhecimento que cabe à historiografia educacional produzir consiste em reconstruir por meio das ferramentas conceituais (categorias) apropriadas, as relações reais que caracterizam a educação como um fenômeno concreto, isto é, como uma 'rica totalidade de relações e determinações numerosas.' (MARX apud SAVIANI, 2007, p. 3, grifos do autor).

Por fim, para que o estudo não se inscreva apenas na análise descritiva e à guisa de conclusão, percebem-se os seguintes pontos que podem ser considerados como preponderantes para avançarmos no conhecimento histórico-educacional e aos quais o pesquisador deve estar atento nos movimentos da investigação expressa, através das relações concretas e caminhos próprios, específicos do objeto que se está estudando:

- A ideologia presente no contexto histórico e, consequentemente, um aprofundamento sobretudo quando são disseminados métodos e orientações pedagógicas como forma de universalização e homogeneidade, via o preceito de igualdade;

- O método de análise, com o intuito de verificar as contradições existentes no período do estudo, a fim de não se incorra no erro de uma análise descritiva com observações e conclusões rasas e precipitadas apenas do aparente, sem reflexões mais complexas e articuladas. (NASCIMENTO; ZANLORENZI, 2017).

Ao trabalhar com a imprensa e a educação, de imediato insere-se em uma parcela significativa de um determinado contexto histórico, presente em uma totalidade complexa, muitas vezes injusta e principalmente contraditória e que, por isso, não se tem nenhuma receita pronta. Cada pesquisador faz o seu caminho e suas escolhas, não existe certo ou errado, apenas escolhas, para não cairmos em um determinismo reducionista ou engessarmos nas instituições, nas práticas ou representações em si mesmo ou para si.

\section{Considerações finais}

Ao trabalhar com pesquisa cientifica é preciso ter como meta a defesa da história, que nada mais é a capacidade do homem de compreender como o mundo veio a ser como é hoje, quais os caminhos que a humanidade pode e deve avançar, e para isso é o historiador, principalmente, quem trabalha com a imprensa.

O texto apresentado não se esgota nesta discussão, pois indicar uma proposta não pode levar a um determinismo e a uma formalidade, muito embora deva haver um método, com procedimentos metodológicos claros, que aponte o caminho que o pesquisador deve seguir.

A finalidade de apresentar uma proposta de análise da imprensa teve o intuito de auxiliar pesquisadores que pretendem utilizá-la como fonte de pesquisa, principalmente em 
fortalecer as pesquisas em história da educação e apontar o movimento entre permanência e mudança em todos os campos.

Conhecer e refletir sobre este processo é primordial, principalmente para reconhecer a multideterminação que envolve a ação humana, e para além das explicações de causas e efeitos, apreender o movimento de totalidade e seus desdobramentos temporais. Outrossim, que o homem é fruto das condições materiais a depender do contexto histórico, cultural, social, econômico e político.

\section{REFERÊNCIAS}

CAPELATO, M. H. R. A imprensa e história do Brasil. São Paulo: Contexto/EDUSP, 1988.

CARVALHO, C. H.; ARAÚJO, J. C. S.; NETO, W. G. Discutindo a história da educação: a imprensa enquanto objeto de análise histórica (Uberlândia-MG, 1930-195). In: ARAÚJO, J. C. S.; JÚNIOR, D. G. (Orgs.). Novos temas em história da Educação Brasileira: instituições escolares e educação na imprensa. Campinas, SP: Autores Associados, 2002.

IANNI, O. A Construção da categoria. Revista HISTEDBR On-line, Campinas, v. 11, n. 41 esp., p. 397-416, abr. 2011. Disponível em:

https://periodicos.sbu.unicamp.br/ojs/index.php/histedbr/article/view/8639917. Acesso em: 16 fev. 2019.

MARX, K. Contribuição à crítica da economia política. 3. ed. São Paulo: Martins Fontes, 2003, p. 248.

MARX, K; ENGELS, F. A ideologia alemã. São Paulo: Boitempo, 2007.

MARX, K; ENGELS, F. Capital: crítica da economia política. Livro I. Volumes 1 e 2. Rio de Janeiro: Civilização Brasileira, 2003.

NASCIMENTO, M. I. M.; ZANLORENZI, C. M. P. Reflexões sobre a pesquisa em História da Educação. In: NASCIMENTO, M. I. M.; ZANLORENZI, C. M. P.; SANTOS, M. L. F. B. dos (Orgs.). História e educação: pesquisas e reflexões. Curitiba, PR: CRV, 2017.

NUNES, C.; CARVALHO, M. M. C. Historiografia da educação e fontes. Cadernos ANPED, Porto Alegre, n. 5, 1993. Disponível em:

http://www.anped.org.br/sites/default/files/caderno_anped_no.5_set_1993.pdf. Acesso em: 16 fev. 2019.

SANFELICE, J. L. Dialética e pesquisa em educação. In: LOMBARDI, J. C.; SAVIANI, D. (Orgs.). Marxismo e educação: debates contemporâneos. Campinas, SP: Autores Associados, 2005.

SAVIANI, D. Breves considerações sobre fontes para a História da Educação. In: LOMBARDI, J. C.; NASCIMENTO, M. I. M. (Orgs.). Fontes, História, Historiografia da Educação. Campinas-SP: Autores Associados, 2004. 
SAVIANI, D. História das ideias pedagógicas no Brasil. Campinas: Autores Associados, 2007.

SAVIANI, D. Pedagogia Histórico-crítica: primeiras aproximações. 11. ed. rev. 1. reimpr. Campinas, SP: Autores Associados, 2012. (Coleção educação contemporânea).

ZANLORENZI, C. M. P; NASCIMENTO, M. I. M. Revista "A Escola": a expressão do liberalismo. In: XI Jornada HISTEDBR. A pedagogia histórico crítica, a educação brasileira e os desafios da sua institucionalização. Cascavel, PR. Anais [...]. Cascavel, PR, 23-25 out. 2013.

ZICMAN, R. B. História através da imprensa: algumas considerações metodológicas Projeto História. Revista do Programa de Estudos Pós-Graduados de História, PUC-SP, v. 4, 1985. Disponível em: https://revistas.pucsp.br/index.php/revph/article/view/12410. Acesso em: 16 fev. 2019.

\section{Como referenciar este artigo}

ZANLORENZI, Claudia Maria Petchak; NASCIMENTO, Maria Isabel Moura. Análise da imprensa como fonte de pesquisa para a História da Educação. Revista Ibero-Americana de Estudos em Educação, Araraquara, v. 15, n. 3, p. 1181-1192, jul./set. 2020. e-ISSN: 19825587. DOI: https://doi.org/10.21723/riaee.v15i3.12706

Submetido em: 26/06/2019

Revisões requeridas em: 28/09/2019

Aprovado em: 02/02/2020

Publicado em: 20/02/2020 